\title{
Clinical and ultrasonographic study of using autogenous venous graft and platelet-rich plasma for repairing Achilles tendon rupture in dogs
}

\author{
A.H. Allawi ${ }^{1}$, L.M. Alkattan ${ }^{1^{*}}$ and O.M. Al Iraqi ${ }^{2}$ \\ ${ }^{1}$ Department of Surgery and Theriogenology, ${ }^{2}$ Department of Internal and Preventive Medicine, College of Veterinary \\ Medicine, University of Mosul, Mosul, Iraq, *Email: laythalkattan@yahoo.com
}

(Received December 30, 2018; Accepted May 12, 2019)

\begin{abstract}
The present article was aimed to assess the healing process of experimental entire rupture of Achilles tendon treated with various methods. The study was conducted on twenty-four healthy mature local breed dogs, which were randomly allocated in equal four experimental groups (6 of each). All dogs underwent complete Achilles tendon rupture and reconstructed as following: Group1 (control), animals were treated with tendorrhaphy only; Group 2, tendorrhaphy with platelet-rich plasma; Group 3, tendorrhaphy with a vein graft; and Group 4, the ruptured tendon was repaired with tendorrhaphy and augmented with vein and platelet-rich plasma. Dogs were monitored clinically and sonographically to evaluate tendon healing at 15,30 and 60 days following the surgery. By comparison with the control group, the utilizing of plasma, with or without vein graft, enhanced the healing process of the induced rapture. Clinically, animals showed a fastest weight bearing and ultrasound imaging revealed increased echogenicity of fibrotic tissue. Clinically, the vein- platelet-rich plasma treated animal's demonstrated early weight bearing, while animal treated with plasma showed earlier improvement in fiber pattern echogenicity. Furthermore, the using of vein graft for injury repair increased the repair process and the healing was earlier than that in the control group. In conclusions, our results suggested that the using of platelet-rich plasma with or without vein graft could enhance tendon healing and improve its mechanical function, which might be attributed to the synergistic effect of platelet-rich plasma with the vein graft.
\end{abstract}

Keywords: Vein graft, Achilles tendon repair, PRP, dogs Available online at http://www.vetmedmosul.com

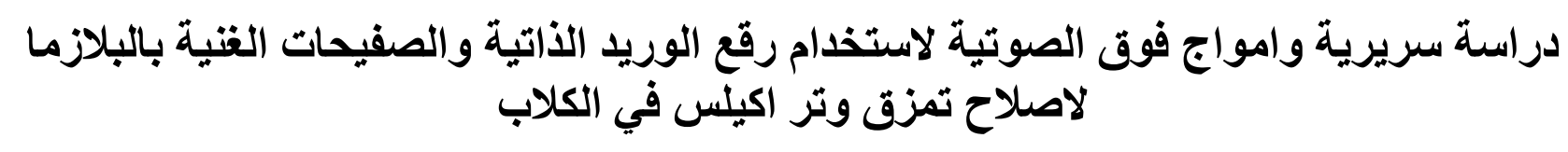

$$
\begin{aligned}
& \text { أسماء حسين علاوي '، ليث محمود القطان' و أسامة موفق العراقي } \\
& \text { ' فرع الجر احة و علم تناسل الحيوان، `فرع الطب الباطني و الوقائي، كلية الطب البيطري، جامعة الموصل، الموصل، العراق }
\end{aligned}
$$

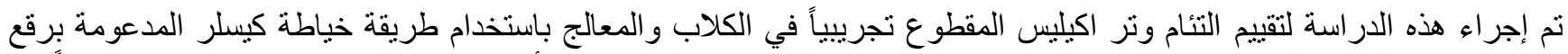

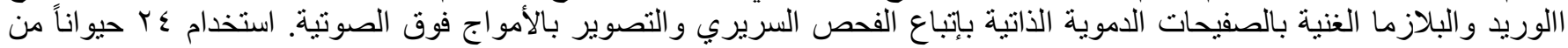

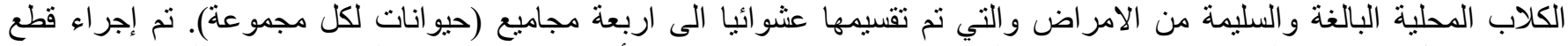

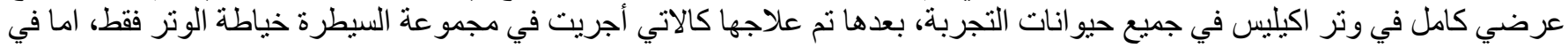

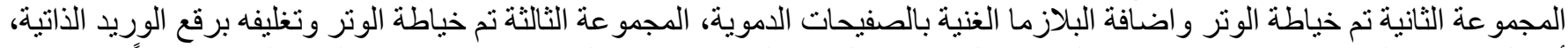

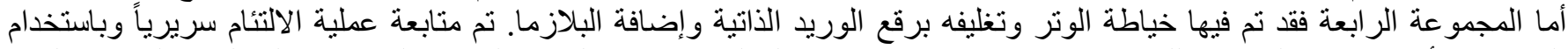

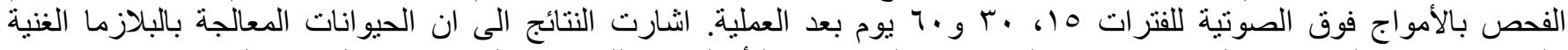
بالصفيحات سواء لوحدها او المقترنة مع رقع الوريد ادت الى تحسين التأم الوتر وذللك من خلال سر عة تحمل وزن الجسم سريريا وتحسن التحن 


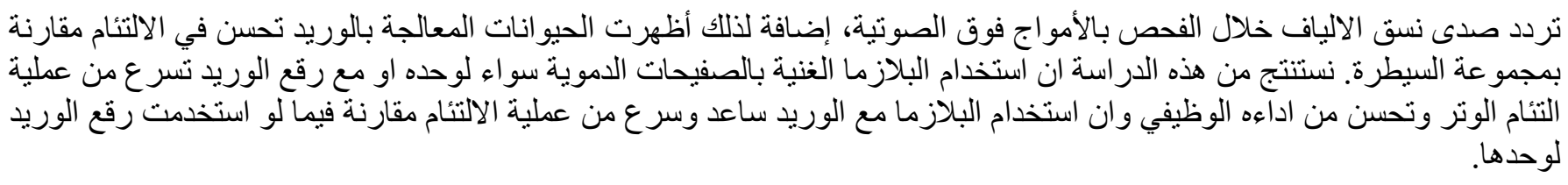

\section{Introduction}

Tendon is a specialized form of dense regular connective tissue, which locates between bone and muscle. Tendon functions to intense the retraction of muscle on a small area of bone work as a shock absorber and have the ability to glide through its surrounding tissues (1). In dogs, Achilles tendon is the strongest and the most predisposed structure of the musculoskeletal system for injuries. It is formed through the assembly of three distinct structures: the tendons of the gastrocnemius muscle, superficial digital flexor muscle and the common tendons of the semitendinosus, biceps femoris and gracilis muscles $(2,3)$. It is a fact that athletes might affect with either partial, complete rupture of the Achilles tendon or malfunction in its biomechanical properties (4). Treatment of Achilles tendon rupture remains a controversial issue and the most frequently applied methods are surgical, percutaneous or conservative repair (5). The most advisable method of treatment is the surgical restoration where structural integrity, strength and mechanical performance of the affected tendon are restored $(6,7)$. However, in tendons, by comparison with other tissues, the progress of healing process is too slow due to the poor blood supply and the high possibility of consequent adhesion that limit the passive and active mobility of the tendon (8). For these reasons, various materials, either synthetic or natural, have been utilized to obtain a superior and earlier healing process with reduced adhesion rates; for instances of these materials are fascia lata (9), pericardium (10), small intestine submucosa (11), vein (12), polypropylene mesh (13), and plasma rich platelets (14). Platelet-rich plasma (PRP) is an autologous concentration of platelets above its normal levels in the whole blood. Degeneration of platelets by an activator causes the release of various physiologically active substances such as fibrinogen, cytokines, clotting factors and locally active growth factors. The released substances are responsible for angiogenesis, migration, proliferation of fibroblast, synthesis of collagen and induce cell differentiation (15). Therefore, it has been used for accelerating the healing of both the hard and soft tissues (16). For examples, it has been used to repair musclotendinous tissues including Achilles tendon, rotator cuff and supraspinatus tendons $(6,14)$. Vein grafts have been used to enhance the recovery of different tissues, such as a carotid artery (17) and musclo-tendinous tissue $(12,18)$. Vein graft was considered as a biological scaffold that forms a source of a cellular component necessary for tissue healing (19). In veterinary medicine, affections of the tendon are usually determined using different diagnostic tools including radiography, ultrasound, and magnetic resonance images. However, ultrasonography remains one of the most popular, practical and diagnostic tools that allows assessing and following up the healing process. Ultrasonography is frequently used in human being and animal's medicine for documentation, differential assessment and grading of Achilles tendon injuries (20). Interestingly, it makes possible to recognize lesions in the soft tissues of limbs by determination the differences in shape, size, echogenicity, and architecture of the affected tendon, ligaments and associated structures (10). Karmer 1997 made the first ultrasonographic examination of Achilles tendon in small animals for diagnosis of orthopedic problems (21). The ultrasonic examination is a safe, non-invasive and inexpensive method that does not require sedation and anesthesia, as in CT scan and MRI; make it more applicable option in the initial diagnosis and follow up examinations. In addition, ultrasound can support other therapeutic procedures of the muscular lesion (22). To date, the using of PRP along with a vein scaffold to repair tendon rupture supported with an ultrasonic assessment of tendon healing has not reported, yet. The aim of the present study is to evaluate the healing of experimental tendon rupture of dogs treated with a vein in the presence or absence of autologous PRP using clinical and ultrasound examination.

\section{Materials and methods}

Local breed dogs $(n=24)$ from both sex with a mean weight and age of $12.2 \pm 0.5 \mathrm{~kg}$ and $16.2 \pm 0.4$ months, respectively, were used. Animals were clinically healthy, had no history or clinical symptoms indicative of neurological or orthopedic defects. Animals were randomly allocated into 4 groups (6 of each) based on the type of treatment received. Group 1, the control group, the tendon was sutured only with Kessler methods by using silk No2. In group 2, tenorrhaphy with adding platelet-rich plasma (PRP), where the tendon was sutured and $2 \mathrm{ml}$ of PRP were applied. In the group 3, vein, the tendon was sutured and wrapped with an already prepared vein graft. The protocol of anesthesia included as a mixture of $10 \%$ Ketamine hydrochloride $10 \mathrm{mg} / \mathrm{kg}$ and $2 \%$ xylazine $3 \mathrm{mg} / \mathrm{kg}$ intramuscularly. 


\section{Preparation of platelet-rich plasma (PRP)}

At the time of operation, $20 \mathrm{ml}$ of blood were withdrawn aseptically from the jugular vein and divided into two $10 \mathrm{ml}$ tubes containing $0.5 \mathrm{ml}$ of $3.2 \%$ sodium citrate. Following centrifugation at $1500 \mathrm{rpm}$ for $10 \mathrm{~min}$, three layers were obtained. The top layer (platelets poor plasma PPP) was pipetted out, thus, the remaining portion of blood represents the PRP $2 \mathrm{ml}$. In order to separate the PRP from the PPP, layers of both tubes were pipetted out and were centrifuged again at $1500 \mathrm{rpm}$ for $15 \mathrm{~min}$. The platelet count was performed in order to assure that the concentration of platelet was 3 times more than the baseline. In order to activate the isolated PRP, two drops of $10 \%$ calcium chloride were added (21).

\section{Preparation of vein grafts}

To harvest the jugular vein graft, a longitudinal skin incision $5 \mathrm{~cm}$ length was made at the lateral aspect of the neck around $5 \mathrm{~cm}$ below the vertical ramus of the mandible. The vein was isolated (Figure 1) and transected after being ligated with double ligation. The harvested venous segment (approximately 3-4 cm long; Figure 2) was kept in a normal saline solution containing gentamycin $10 \%$. The donor site was routinely closed. Surgical procedure (tendon defect and reconstruction). The site of operation was prepared routinely under aseptic condition; animals were placed on lateral recumbency and a longitudinal $5 \mathrm{~cm}$ long skin incision was made over the Achilles tendon starting just 2 $\mathrm{cm}$ proximal to the tuber calcaneus. The Achilles tendon was isolated and completely severed transversely with a scalpel. Tendon ends were approximated with Kessler locking loop pattern sutures using silk No 2 . The vein was incised longitudinally, wrapped transversally; averted agonist to the tendon and the proximal and distal free edges of the grafted vein was sutured to tendon by 2-0 silk with interrupted stitches (Figure 3). In the group 4, vein-PRP, the tendon was treated similar to group 3 and $2 \mathrm{ml}$ of PRP was applied. In all groups, the site of operation was routinely closed, and the operated limb was immobilized using Gypsona (leaving a window) for 2 weeks postoperatively.

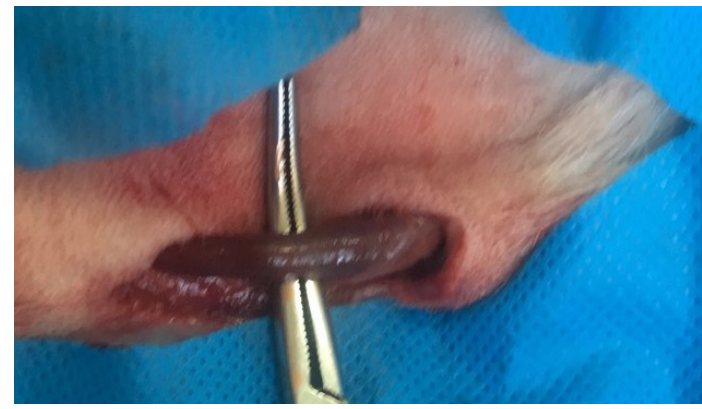

Figure 1: Show the isolation of the vein and double ligation
Animals were monitored clinically for 60 days following the operation. Lameness was scored according to the lameness numeric rating scale (gamble) criteria. For each animal, to compare the outcomes with ultrasound images, both tendons were scanned at longitudinal projections in a static view starting with the probe positioned longitudinally on the Achilles tendon. Changes in echogenicity and fiber pattern were used to estimate responses of animals to treatment.

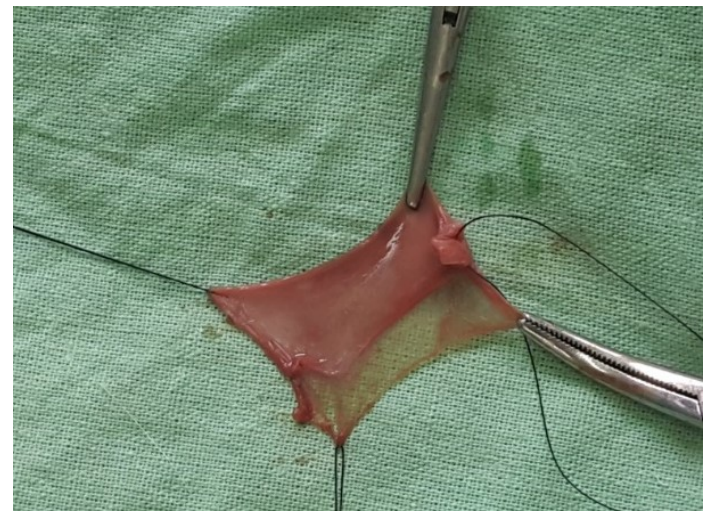

Figure 2: Harvested venous segment

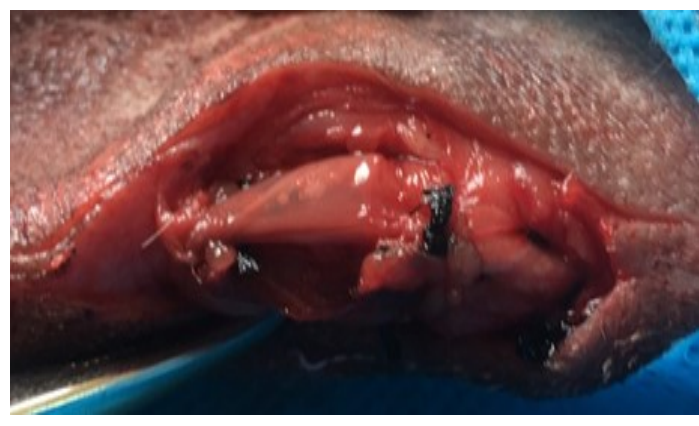

Figure 3: Show's tendon reinforced with vein graft

\section{Results}

Clinical examination of all experimental animals exhibited normal effectiveness and appetite, with the exception of two animals in the control and the vein group where they showed sluggishness during the first two days. Consequently, their condition has improved in terms of anorexia and effectiveness. In all groups, there was no evidence of developed outward signs of wound complications such as infection or wound dehiscence. All animals showed minimal weight bearing on the affected limb and demonstrated a severe second degree of lameness at walking and jogging. This degree of lameness remains obvious for several days and varied according to the treatment group (control: 10-15, PRP: 8-9, vein: 9-12, vein- 
PRP: 7-8 days). Animals demonstrated a gradual improvement in their mobility, where only a perceptible lameness was obvious at jogging, which accounted as the first degree of lameness. This observation was also varied among groups which lasts for 30 (control), 20 (PRP), 20-23 (vein) and 15-18 (vein-PRP) days after treatment. Interestingly, animals among groups revealed various periods of regaining weight-bearing ability and the using of the affected limb without any obvious signs of lameness after 55 (control), 39 (PRP), 45 (vein) and 37 (vein-PRP) days after the operation. During the physical inspection of the operation site, by comparison with control and plasma treated groups, a noticeable thickening in the tendon treated with vein graft were detected. However, the thickness in the control group was more than that in the plasma treated group. The thickening in all groups was reduced gradually and disappeared at 23-25, $18-19,30-31$ and 25-30 days after the operation in control, PRP, vein, and vein -PRP treated groups, respectively.

After 15 days of treatment, the ultrasonic imaging of the whole tendon length in the control group revealed a heterogeneous fiber pattern with an area of hypoechogenicity, which was more than other groups. After 30 days, the hypoechoic area remained visible and the tendon appeared slightly hypoechoic compared with that observed at 15 days. After 60 days post-treatment, the ultrasonography showed a homogenous fiber pattern with hyperechoic foci (Figure 4). In the PRP treated group, ultrasonography examination at the 15 days post-surgery, the tendon showed a heterogeneous fiber pattern with an area of a considerable reduced echoic in comparison with the control group. At day 30, homogenous fiber pattern was observed, while at 60 days, an intact tendon echogenicity was revealed (Figure 5). In the vein treated group, at the $15^{\text {th }}$ postoperative day, the ultrasound imaging revealed the presence of a hyperechoic mass with the hypoechoic center. At the $30^{\text {th }}$ day following treatment, in addition to the described finding, a hyperechoic line of fibrosis was observed, which remains distinguished at the day 60 (Figure 6). Interestingly, in the group treated with vein graft and PRP, the hypoechoic mass, hypoechoic center, and homogenous mass were observed at $15^{\text {th }}, 30^{\text {th }}, 60^{\text {th }}$ days post-operative, respectively, (Figure 7).

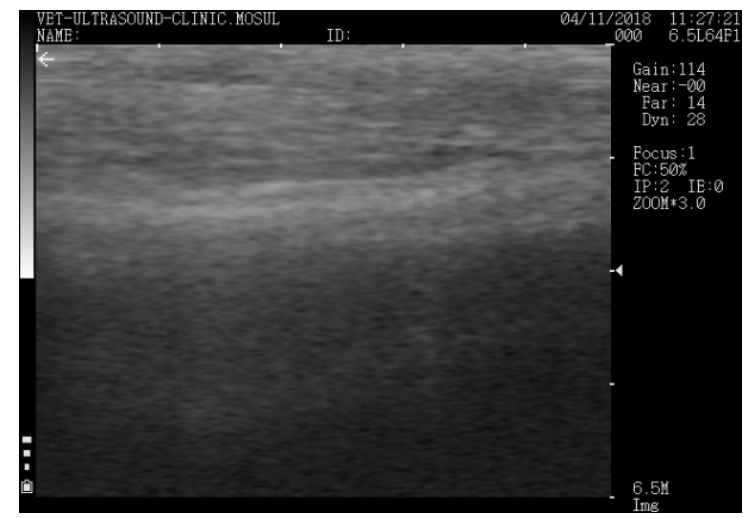

Figure 4 A: longitudinal ultrasound scans of the lateral aspect of canine calcaneal tendon in control group at 15 days. Heterogeneous fiber pattern with an area of hypoechogenicity.

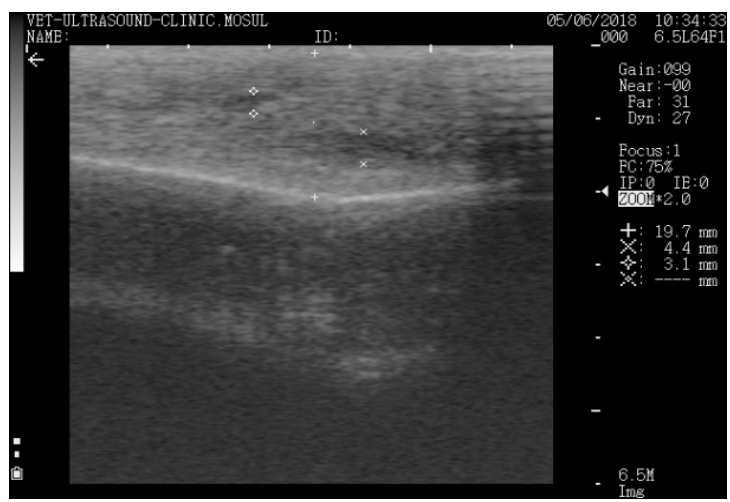

Figure $4 \mathrm{~B}$ : Longitudinal ultrasound scan of the lateral aspect of canine calcaneal tendon in the control group at 30 days. Heterogeneous fiber pattern with an area of hypoechogenicity and a hyperechogenicity.

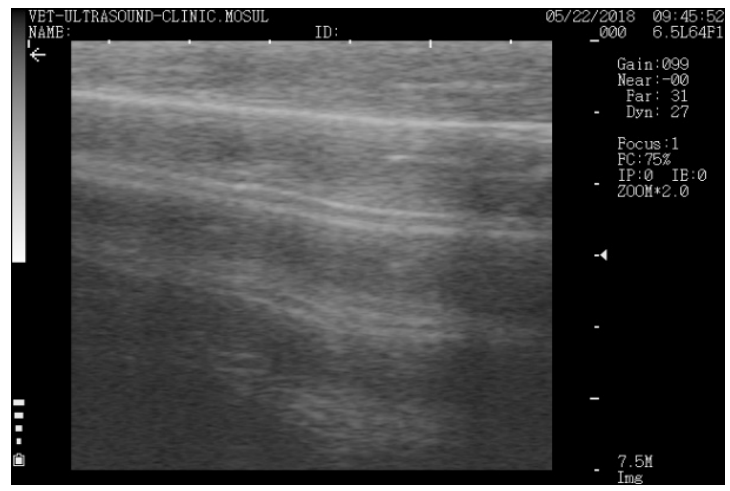

Figure $4 \mathrm{C}$ : Longitudinal ultrasound image of a lateral aspect of the canine calcaneal tendon in control group at 60 days. Homogenous fiber pattern with an area of with hyperechogenic. 


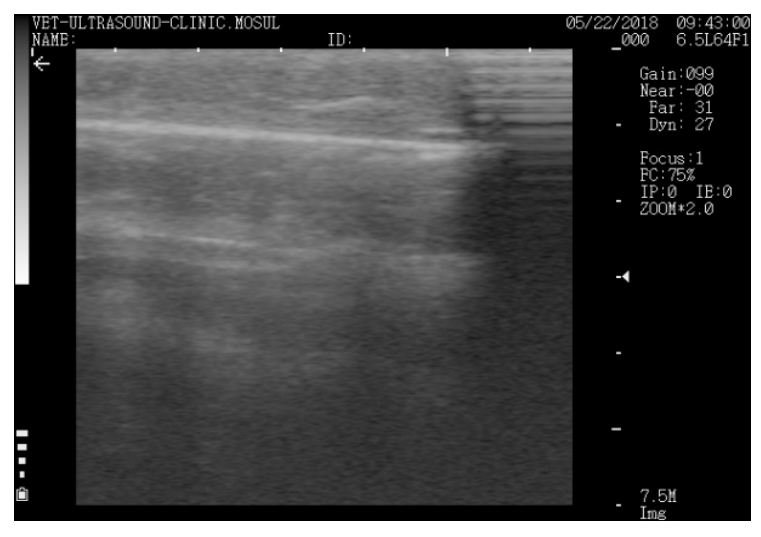

Figure 5 A: Longitudinal ultrasound scan of the lateral aspect of canine of the canine calcaneal tendon in plasma group at 15 days. Heterogeneous fiber pattern with an area of the hypoechogenic.

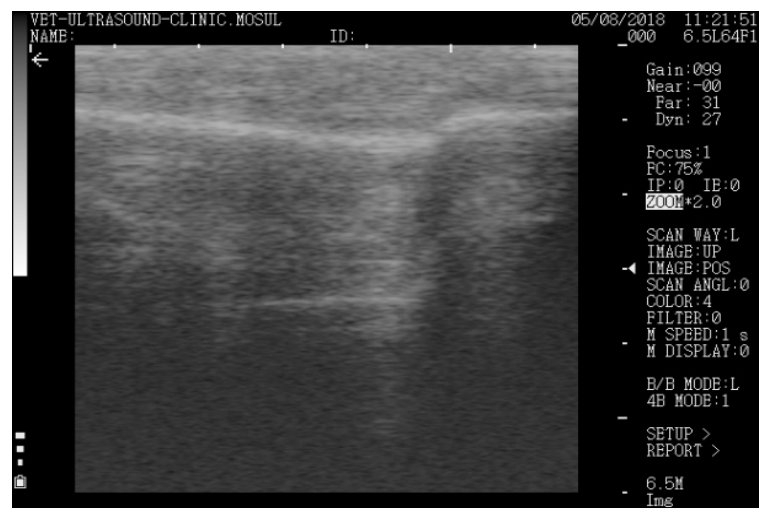

Figure 5 B: Longitudinal ultrasound scan of the lateral aspect of canine calcaneal tendon in plasma group at 30 days, homogenous fiber pattern.

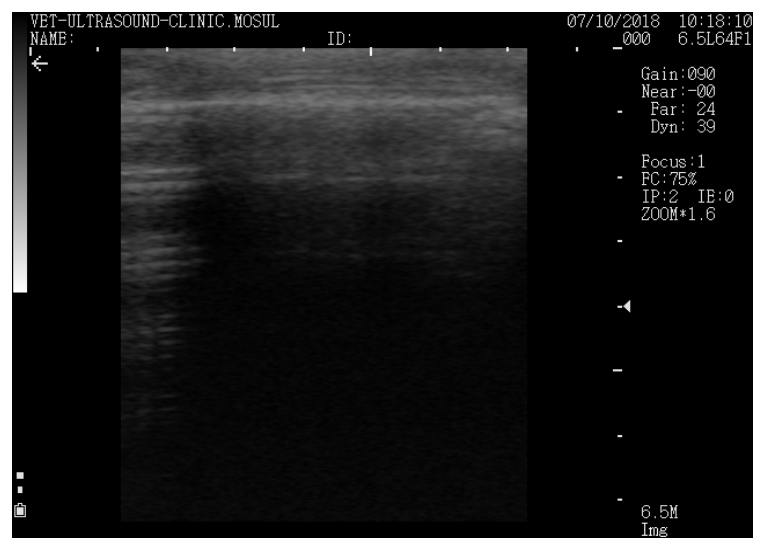

Figure $5 \mathrm{C}$ : Longitudinal ultrasound scan of the lateral aspect of canine calcaneal tendon in plasma group at 30 days, intact tendon echogenicity.

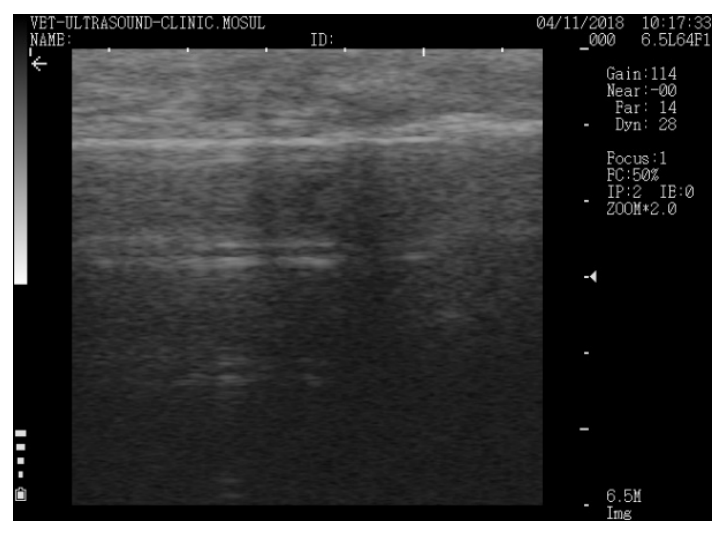

Figure 6 A: Longitudinal ultrasound scan of the lateral aspect of canine tendon in vein group at 15 days PO, hyperechoic mass with a hypoechoic center.

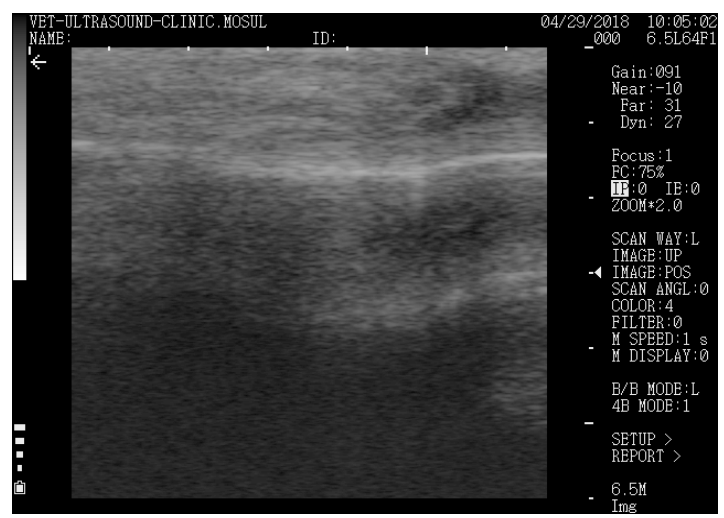

Figure 6 B: Longitudinal ultrasound scan of the lateral aspect of canine calcaneal tendon in vein group at 30 days PO. Hyperechoic mass hypoechoic center and hyperechoic line of fibrosis.

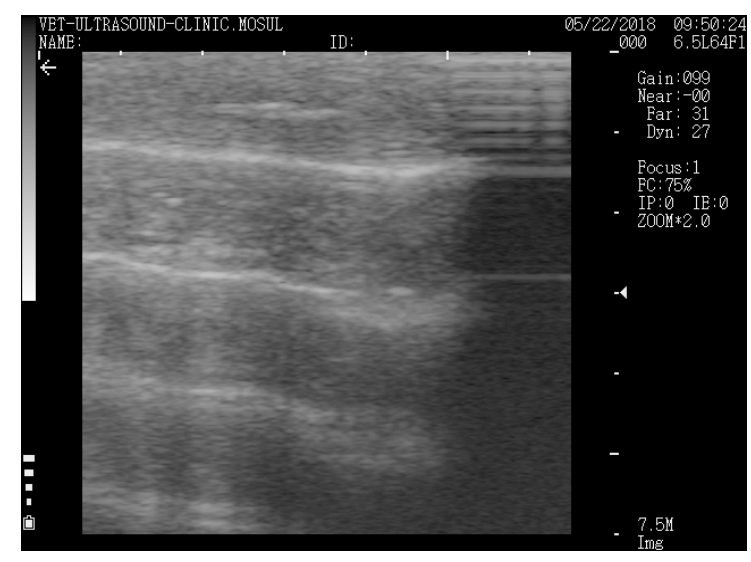

Figure $6 \mathrm{C}$ : Longitudinal ultrasound scan of the lateral aspect of canine calcaneal tendon in vein group at 60 days PO, a hyperechoic line of fibrosis. 


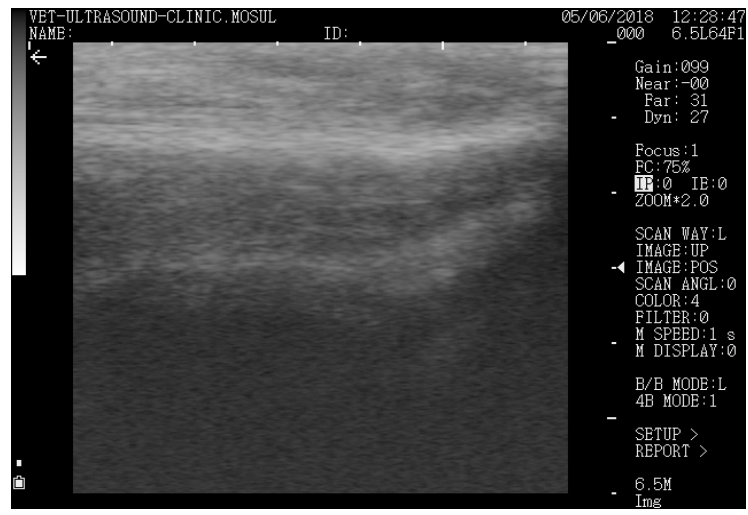

Figure 7 A: Longitudinal ultrasound scan of the lateral aspect of canine calcaneal tendon in vein and plasma group at 15 days $\mathrm{PO}$, hypoechoic mass.

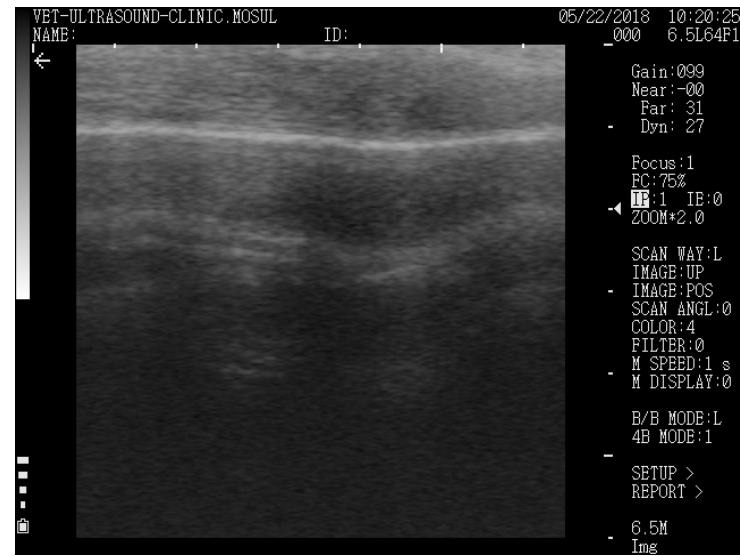

Figure $7 \mathrm{~B}$ : Longitudinal ultrasound scan of the lateral aspect of canine calcaneal tendon in vein and plasma group at 30 days PO, hypoechoic center.

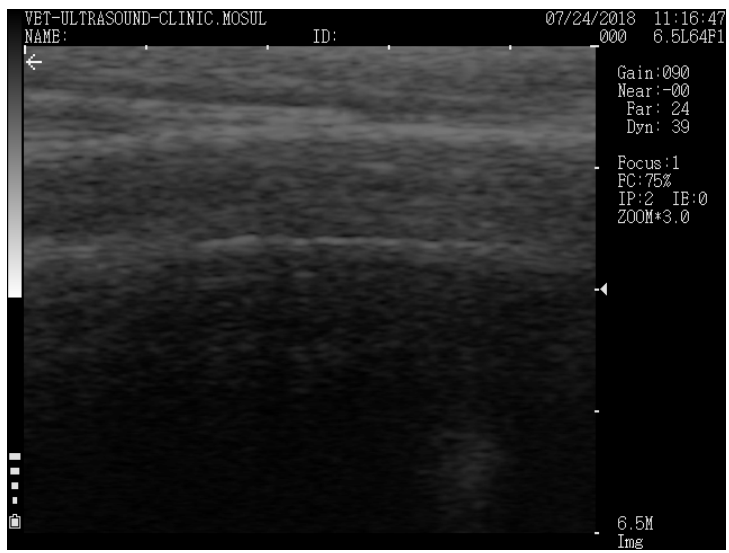

Figure $7 \mathrm{C}$ : Longitudinal ultrasound scans of the lateral aspect of canine calcaneal tendon in vein group at 60 days PO, show homogenous mass.

\section{Discussion}

The process of tendon repair is generally very slow and characterized by adhesions and scar tissue formation (23). Therefore, the successful repair of a ruptured tendon is challenging because of the tension, retraction of the muscle, or poor suture holding. All these factors are contributing to the gap formation, decreasing the tensile strength and consequently the re-rupture of the tendon (24). In the current study, both clinical and sonographic examinations demonstrated the valuable benefits of using different autologous scaffold (PRP, vein, and vein -PRP graft) in the treatment of Achilles tendon rupture. One of the most important clinically relevant findings was that animals treated with PRP, or PRP and vein, accomplished a faster healing and adequate tendon tissue regeneration than those in other groups. This finding might indicate that PRP has the effectiveness to accelerate tendon healing where its efficacy could be attributed to the local delivery of a wide range of growth factors and proteins (14). This finding broadly supports the work of other studies stated that using platelet-rich plasma is essential in the process of tendon healing and accordingly restoring its function. A possible explanation for this effect might be due to the release of growth factors following platelets activation $(6,16)$. Growth factors regulate and stimulate cellular processes during healing. Furthermore, the fibrin clot of PRP provides a matrix for the migration of cells responsible for healing $(14,25)$. Our results are also consistent with findings obtained in previous studies reported that the using of PRP alone or combined with other types of the graft can shorten the required time for tendon healing $(6,14)$. In this study, the using of PRP with the vein grafts produced a synergic effect resulting in improvement of tendon healing, where the vein provided the mechanical support, while PRP provided the biological enhancement. However, the healing process in the vein treated group was earlier than in control group; this outcome is in agreement with a previous in dogs, which also reported a difference between tendon healing in the control and vein treated group (12). The use of biomaterial as a graft might provide support for the host tissue in growth, increase cellular differentiation and induced a site-specific remodeling for several kinds of connective tissues. The regenerative process led to the formation of tissue, which is functionally and structurally similar to the original tissue (26). In addition, the vein graft acts as a protective shelter which might function to decrease adhesion formation, and thus, maintaining the gliding movement of the tendon. Moreover, it may work as a source of cellular elements that enhances tendon repair (12). Ultrasound is commonly used to examine Achilles tendon because of its superficial position and easy accessibility that allows obtaining images of precise details, which include tendon width, its sheath swelling, collagen 
integrity, vascularity, changes of water content within the tendon and/or peritendon (27). Achilles tendon healing can be assessed by sonography through several criteria including changes in fiber pattern, echogenicity and the typical internal echo structure results from the reflection of sound waves (27).

In all groups, at the day 15 th postoperative, it was observed that the treated tendon was thicker than the normal one, especially in control and animals treated with vein graft; the tendon size is thought to be increased sonographically in acute and chronic tendon diseases, because of etiopathology changes in the tendon (14). Furthermore, by comparison with other treated groups, we observed that the tendon in the control group showed hypoechogenicity; whereas, the lesser hypoechogenicity was in the plasma treated group. The hypoechogenicity might explain either due to the presence of intra-tendinous edema, which is commonly associated with acute tendinopathies or as an indicative sign for hemorrhage. In the present study, the edema might have a role in tendon enlargement (14). In addition, the detection of hyperechoic mass in all graft treated groups, except in the control group, might indicate that the fibrous connective tissue was formed at the surgical site (14). In control and plasma treated groups, heterogeneous fibers pattern was also prominent, and this could be considered as an indicative sign of an intra-tendinous tear, which might also explain the presence of edema between the tendon fibers. Secondly, it might also serve as an indicator of mini degenerative changes in the tendon's collagen, which is signifying by fiber discontinuity. The presence of these micro-tears at a particular site might lead to weakening the tendon's tensile strength (14). At the day 15th following treatment, the improvement in tendon healing was noted sonographically in all groups, especially in PRP treated group. The progress in healing may be attributed to the increased formation and organization of the mature collagen, this result reflects data from previous researchers (14). At the day 30th postoperative, there was a difference between groups in relation to the persisted hypoechogenicity, which was associated with decreased tendon inflammation in all groups except in the PRP treated group. Regions of hyperechogenicity that observed in vein and control group revealed the evidence of connective tissue formation, scar tissue, chronicity or intra-tendinous calcification, which may be recovered gradually $(14,22)$. Homogenous fiber pattern was observed only in the plasma treated group, which might be indicative of mature connective tissue formation. At the day 60th postoperative, the improvement in tendon healing was particularly observed in PRP group; while in the vein treated group, a line of echogenicity was distinguished, indicating that the healing of tendon was completed peripherally. At the day 60 postoperative, ultrasonography revealed enhancement in the echogenicity and fiber pattern in animals treated with PRP, whereas, the vein-PRP treated group showed a higher echogenicity than other groups. The hyperechoic parallel lines represented to the collagen fibers (3). It was suggested that PRP can improve tendon healing by increasing the number of fibroblast proliferation and collagen production $(14,22)$. A previous study provided important information on a relationship between echogenicity and collagen fibers during Achilles tendon healing and indicated a difference in the degree of echogenicity according to the type of the formed collagen (27). Furthermore, the early weight bearing in the vein-PRP treated group might be attributed to the increased tendon stiffness due to the increased amount of collagen type 111, which has hyperechoic properties. However, in the PRP treated group, the sonography showed the echo intensity, which might refer to that PRP can provide both the biological improvement and mechanical augmentation (6). The improved tendon healing in the vein treated group can be linked to its collagen and cellular component (12).

\section{Conclusion}

Our results suggested that the using of platelet-rich plasma with or without vein graft could improve tendon healing and restore its function, which might be attributed to the synergistic effect of platelet-rich plasma with the vein graft.

\section{Acknowledgement}

This study was supported by the College of Veterinary Medicine, University of Mosul, Iraq.

\section{References}

1. Saini NS, Roy KS, Bansal PS, Singh B, Simran PS. A preliminary study on the effect of ultrasound therapy on the healing of surgically severed Achilles tendons in five dogs. J Vet Med. 2002;49: 321-328. doi.org/10.1046/j.1439-0442.2002.00441.x

2. Fahie MA.Healing, diagnosis, repair, and rehabilitation of tendon conditions. Vet Clin Small Anim. Pract. 2005;35: 1195-1211. DOI: 10.1016/j.cvsm.2005.05.008

3. Lamb $\mathrm{C}$ and Duvernois A. Ultrasonographic anatomy of the normal canine calcaneal tendon. Vet Radio and Ultrasound. 2005;46(4): 326330. DOI: $10.1111 / \mathrm{j} .1740-8261.2005 .00061 . \mathrm{x}$

4. Gungormus C, Cetinkaya MA, and Demirutku. A new model for partial immobilization of rat hind limb after Achilles tendon excision/interposition. Turk J of Vet and Anim Scie. 2013;37: 546552. DOI: $10.3906 /$ vet-1206-8

5. Maquirriain J. Achilles Tendon Rupture: Avoiding Tendon Lengthening during Surgical Repair and Rehabilitation. Yale J Biol Med. 2011;84(3):289-300.

6. SarrafianT L, Wang Hackett HS, Yao J Q, Shih MS and Ramsay H L. Comparison of Achilles Tendon Repair Techniques in a Sheep Model Using a Cross-linked Acellular Porcine Dermal Patch and Platelet-rich Plasma Fibrin Matrix for Augmentation. J of Foot \& Ankle Surg. 2010;45:128-134. DOI: 10.1053/j.jfas.2009.12.005 
7. Taniguchi1 YU, Yoshioka T, Sugaya H, Kanamori A, Gosho M, Aoto $\mathrm{K}$, Yamazaki M. Intra-articular platelet-rich plasma (PRP) injections for treating knee pain associated with osteoarthritis of the knee in the Japanese population: a phase I and IIa clinical trial. Nagoya J Med Sci. 2018;80: 39-51. DOI: 10.18999/nagjms.80.1.39

8. Jahani S1, Moslemi HR, Dehghan M. The effect of butyric acid with autogenous omental graft on the healing of experimental Achilles tendon injury in rabbits. Iranian J of Vet. Res. 2015;16( 50):100-104.

9. Atalan G, Cihan M, Demirkan I and Sozmen M. Surgical treatment of musculus gastrocnemius tendon rupture by use of tensor fascia lata autograft: An experimental study of rabbit model. Kafkas Univ vet fag Derg. 2003;9(1):23-28

10. Dal-Bó IS, Ferrigno SR, Macedo AS, Paes JF., Marinho PV, Bregadioli Th and GaleazziVS. Tenorrhaphy of the Common Calcaneal Tendon in Dogs and Cats: case report. Acta. Scie. Vet. 2016;44(1 1):144. DOI:10.22456/1679-9216.84404

11. Phipatankul WP, Petersen SA. Porcine small intestine submucosa xenograft augmentation in the repair of massive rotator cuff tears. Am J Orthp. 2009;38 (11):572-575.

12. Daradka MH, Malkawi MA, Ismail ZB and Alshehabat MA. Autologous venous grafting promotes healing and reduces adhesion formation in experimentally severed canine superficial digital flexor tendons. Bulgar J of Vet Med. 2016;19( 3):233-241.

13. Spinella1 G, Tamburro R, Loprete G, Vilar J, Valentini S. Surgical repair of Achilles tendon rupture in dogs: a review of the literature, a case report and new perspectives. Vet Med. 2010;55(7):303-310.

14. McDougall R.A, Canapp S.O and Canapp D. A. Ultrasonographic Findings in 41 Dogs Treated with Bone Marrow Aspirate Concentrate and Platelet Rich Plasma for a Supraspinatus Tendinopathy: A Retrospective Study. Frontiers in Veterinary Science .2018;5(98) :110. doi.org/10.3389/fvets. 2018.00098

15. Malik A, Tabassum R, Ahmad M. Autogenous platelet-rich plasma in the healing of bone defects. World $\mathrm{J}$ of Med and Med Sci Res .2013;1(5): 082-084.

16. Rha DW, Park GY, Kim YK, Lee SC. Comparison of the therapeutic effects of ultrasound-guided platelet-rich plasma injection and dry needling in rotator cuff disease: a randomized controlled trial. Clin Rehabi. 2013;27(2):113- 122. doi: 10.1177/0269215512448388.
17. Sandusky GE, Badylak SF, Morff RJ. Histologic findings after in vivo placement of small intestine submucosa vascular grafts and saphenous vein grafts in the carotid artery in dogs. Am. J. Pathol. 1992;140:317-324

18. Mousavi SR, Mehdikhah Z. and Tadayon N. Flexor tendon repair in children with zone 2 injuries: An innovative technique using autogenous vein. J of Ped Surg. 2009;44:1662-1665.

19. Hosgood G. Wound repair and specific tissue: In Slatter D. Textbook of Small Animal Surgery. 3rd ed. Saunders, Philadelphia. 2003:6684.

20. Henderson RE, Walker BF and Young KJ. The accuracy of diagnostic ultrasound imaging for musculoskeletal soft tissue pathology of the extremities: a comprehensive review of the literature. Chiropractic \& manual therapies. 2015;23(1) pp.31. DOI: 10.1186/s12998-015-00765

21. Kramer M., Gerwing M., Hach V., Schimke E. Sonography of the musculoskeletal system in dogs and cats. Vet. Radio. Ultrasound. 1997; 38:139-149. DOI: 10.1111/j.1740-8261.1997.tb00829.x

22. Gamble LJ, Canapp DA, Canapp SO. Evaluation of Achilles tendon injuries with findings from diagnostic musculoskeletal ultrasound in canines -43 cases. Vet Evidence .2017; 2(3):1-23.

23. James R, Kesturu G, Balian G, Chhabra A. Tendon: biology, biomechanics, repair, growth factors, and evolving treatment options. J of Hand Surg. 2008;33:102-112. DOI:10.1016/j.jhsa.2007.09.007

24. Alam MR, Gordon WJ, Heo SY. Lee KC, Kim NS, Kim MSand Lee HB. Augmentation of a ruptured tendon using fresh-frozen Achilles tendon allograft in two dogs: a case report. Vet Med. 2013;58(1):5055. DOI: $10.17221 / 6656$.

25. Barker S, Bell S, Connell D. Ultrasound-guided platelet-rich plasma injection for distal biceps tendinopathy. Shoulder Elbow J. 2015;7(2):110-114. DOI:10.1177/17585732145675588.

26. Greca F.C, Ramos E. J, Dallolmo V.C. Evaluation of Porcine Small Intestinal Submucosa in Achilles Tendon Repair.The J.of Applied Res. 2005;5( 1 ):115-123.

27. Khasru M R, Nazrin F,Siddiq M, Marzen T, AnwarN,Haseen F, Moniruzzaman M, Jahan I, Ahsan Ullah M, Rahman S and Sale A. Diagnosis of Achilles Tendon Pathology: Ultrasonography Versus Plain X-ray. Brit J of Med \& Med Res.2017;19(12): 1-10. DOI:10.9734/BJMMR/2017/31501 